\title{
EVOLVING WITH CONTEMPORARY CONTRACT RESEARCH
}

\section{During the past 25 years, the role of a large contract research organization (CRO) has evolved to offer a full range of drug development services}

In 1995, the pharmaceutical company that I was working for was purchased by a larger competitor who, after a period of re-engineering, sold part of their acquisition to a contract research organization (CRO). At that time, my experience of CROs was limited, encountering them only when project teams that I had served on had outsourced selected preclinical work. Some former colleagues advised me to leave, holding the view that contract research was a 'mindless activity' fit only for automatons. However, others pointed to an evolving industry, offering a diverse range of services that were increasingly being outsourced by both biotech and larger pharmaceutical companies. Faced with the prospect of further uncertainty due to mergers and acquisitions in the sector, I decided to stay.

Consequently, my colleagues and I rapidly converted from a preclinical R\&D group to a business unit offering services on a contractual basis. Moving from a cost centre to a profit centre creates many challenges, including defining key products, estimating market size, costing study proposals, creating a client base and informing potential clients of your capabilities. In terms of helping to secure new business, I was fortunate in being able to draw on a global network of ex-colleagues and other contacts in pharmaceutical companies, formed during my time in the industry .

For many years, I had worked in research laboratories, unconsciously enjoying a relative degree of freedom to pursue original ideas linked to compound development. So, it was, and to some extent still is, difficult to adjust to a more regulated environment, working with compounds whose discovery and patenting occurs elsewhere. However, the development of good working relationships with many different clients provides an interesting insight into the range of different approaches to drug development and allows negotiation of not only straightforward 'fee-forservice' contracts, but also of longer-term arrangements. These agreements might, for example, offer the utilization of a group of full-time employees for a period of time. This provides a greater degree of flexibility within the project, while being both cost-effective for the client and providing a consistent revenue stream for the CRO. Arrangements of this type can allow for the development of new experimental pharmacology models, assignment of long-term research projects or provision of regular data sets from prolonged screening programmes, all using groups of experienced individuals.

Crucial to the success of these kinds of collaborations is client confidence in the scientific credibility and expertise of the $\mathrm{CRO}$ group. Indeed, recruitment and retention of postgraduate or postdoctoral staff with previous experience in the pharmaceutical industry plays a key role in a CRO maintaining its competitive position. Industry expects to engage with individuals who can assess and resolve problems, and can also add value. My experience has been that intellectual input is welcomed by both biotech and major pharma, particularly when a company is unfamiliar with the limitations of a specific model used to predict therapeutic efficacy. In fact, niche contract companies often provide a greater degree of expertise than can be recruited on the open market, and this has led to examples of individuals eventually being employed permanently by their sponsors.

Traditionally, pharmaceutical companies have outsourced services in core areas that are heavily regulated, such as clinical trials management or preclinically in the areas of toxicology, drug metabolism and safety pharmacology. However, with the enormous pressure faced by the industry to increase the number of new chemical entities that enter full development, larger CROs have expanded their portfolios, and offer expertise in virtually all areas of drug development. This includes marketing and sales, database management, preclinical research and consultan$\mathrm{cy}$, as well as offering companies access to experienced project teams charged with expediting development times.

A logical extension of the role of a major CRO is therefore to consider commercialization or partnering opportunities with companies that have one or several products in development. Difficulties in obtaining biotech financing, and growing costs associated with developing products to registration, now mean that innovative partnering opportunities are arising earlier in compound development. So, the internal scrutiny of projects through due diligence, conducted by independent experts from a CRO, can enable rapid, optimal risk assessment of projects. Indeed, many expharma senior staff now work successfully in large CROs and have, collectively, a formidable accumulation of experience concerning drug evaluation across all disciplines, developed during many years in the pharmaceutical industry, enabling rapid, critical appraisal of projects at different levels. Significantly, this activity can be most valuable in underwriting or triggering financial decisions made by venture capital groups, building trust and confidence with both investors and development groups alike. In undertaking these activities, some CROs can find themselves 'well placed' to judge potentially 'winning compounds' early on, and to recommend licensing opportunities to sponsors, or to take an equity position in compounds or companies at an earlier stage. Such activities can only enhance the exit strategies for small pharmaceutical companies as they look to license-on promising products at Phase II.

The role of a large, modern CRO, offering a full range of development services, has evolved far beyond the traditional fee-for-service contract established more than 25 years ago. Large CROs now offer a unique and dynamic environment in which to work, with increasing opportunities to develop longer-term partnerships with both biotech and major pharma.

Ian Chapman
eH14 4 AP, UK. quintiles.com
Ian Chapman, Scientific
Director, Pharmacology, Quintiles Ltd, Heriot-Watt University Research Park Riccarton, Edinburgh, 